\title{
Adaptive thermoregulation during summer in two populations of an arid-zone passerine
}

\author{
B. Smit, ${ }^{1,3}$ C. T. Harding, ${ }^{2}$ P. A. R. Hockey, ${ }^{2}$ and A. E. McKechnie ${ }^{1}$ \\ ${ }^{1}$ DST/NRF Centre of Excellence at the Percy FitzPatrick Institute, Department of Zoology and Entomology, University of Pretoria, \\ Private Bag X20, Hatfield 0028 South Africa \\ ${ }^{2}$ Percy FitzPatrick Institute of African Ornithology, DST/NRF Centre of Excellence, University of Cape Town, \\ Rondebosch 7701 South Africa
}

\begin{abstract}
Heterothermy plays an important role in lowering the costs of thermoregulation in endotherms by reducing water and energy requirements. We tested predictions that birds in arid habitats should express fine-scale variation in their thermoregulatory patterns as a function of prevailing climatic conditions. We assessed effects of air temperature $\left(T_{\text {air }}\right)$ and water vapor pressure deficit $(D)$ on body temperature $\left(T_{\mathrm{b}}\right)$ in free-living White-browed Sparrow-Weavers (Plocepasser mahali) during summer in two arid habitats in the Kalahari Desert, South Africa, using data from a dry period at a hot, desert site ( $n=7$ birds), and during a dry period ( $n=4$ birds) and a wet period ( $n=5$ birds) at a milder, semi-desert site. The desert birds maintained a significantly higher set-point $T_{\mathrm{b}}\left(41.5^{\circ} \pm 0.2^{\circ} \mathrm{C}\right.$, mean $\left.\pm \mathrm{SD}\right)$ than semi-desert birds $\left(40.2^{\circ} \pm 0.2^{\circ} \mathrm{C}\right)$. During the warmest part of day (12:00-18:00 hours), $T_{\mathrm{b}}$ increased significantly during periods of high $T_{\text {air }}$ and/or high humidity, and mean and maximum $T_{\mathrm{b}}$ were up to $1.4^{\circ}$ and $2.3^{\circ} \mathrm{C}$, respectively, above normal levels. However, as $T_{\text {air }}$ increased, birds at the desert site maintained $T_{\mathrm{b}}$ at or below set-point levels for a greater proportion of the time than birds at the semi-desert site. Birds at the desert site also expressed a greater magnitude of daily heterothermy (heterothermy index, $\mathrm{HI}=2.4^{\circ} \pm 0.3^{\circ} \mathrm{C}$, mean \pm $\mathrm{SD})$ than birds at the semi-desert site: the latter population showed a greater magnitude of heterothermy during a dry period $\left(\mathrm{HI}=2.1^{\circ} \pm 0.3^{\circ} \mathrm{C}\right)$ than during a wet period $\left(\mathrm{HI}=1.6^{\circ} \pm\right.$ $0.2^{\circ} \mathrm{C}$ ). Birds continued foraging throughout the warmest part of the day, despite the fact that heat dissipation (percentage of time spent panting and wing-spreading) increased significantly with increasing $T_{\text {air. }}$. Our findings reveal that populations can vary in their thermoregulatory responses in both space and time and suggest that small changes in $T_{\text {air }}$ can have significant effects on thermoregulation in free-ranging desert birds, even when $T_{\text {air }}<T_{\mathrm{b}}$. These data have important implications for assessing vulnerability of species to climate change, suggesting that sensitivity should be assessed at the population, rather than species, level.
\end{abstract}

Key words: climate change; heat dissipation; heterothermy; hyperthermia; Kalahari Desert, South Africa; Plocepasser mahali; thermoregulation; White-browed Sparrow-Weaver.

\section{INTRODUCTION}

An organism's body temperature $\left(T_{\mathrm{b}}\right)$ has farreaching consequences for its short- and long-term performance, and hence fitness, and many animals have evolved the capacity to regulate an optimal $T_{\mathrm{b}}$ via behavioral and/or physiological mechanisms. For endotherms, $T_{\mathrm{b}}$ regulation occurs continuously, often under varying conditions, and sometimes at extreme temperatures that are far outside the thermoneutral zone. In the last two decades, a proliferation of data on daily and seasonal $T_{\mathrm{b}}$ variation in endotherms (especially studies on free-living animals) has revealed $T_{\mathrm{b}}$ to be a dynamic trait, tightly linked to an endotherm's interactions with its environment (reviewed by Angilletta et al. 2010). For

Manuscript received 5 September 2012; revised 6 December 2012; accepted 12 December 2012; final version received 4 January 2013. Corresponding Editor: T. D. Williams.

${ }^{3}$ E-mail: smitbe@gmail.com example, plasticity in $T_{\mathrm{b}}$ regulation both within and among populations has been observed in the Australian bush rat (Rattus fuscipes), with set-point $T_{\mathrm{b}}$ (the most frequently regulated body temperature) lower in winter than in summer (Glanville and Seebacher 2010), and lower in populations inhabiting colder climates (Glanville et al. 2012).

Angilletta et al. (2010) argued that thermoregulatory variation in endotherms is largely adaptive, and that $T_{\mathrm{b}}$ should be maintained or varied in response to ecological and energetic costs and benefits associated with thermoregulation. Birds and mammals need to expend considerable amounts of energy on thermogenesis when the effective environmental temperature is below the lower bound of the thermoneutral zone (TNZ), and they face potentially high rates of water loss (for evaporative cooling) when environmental temperature exceeds the upper bound of the TNZ (Withers 1992). The increased costs or decreased benefits of homeothermy should thus favor either a change in set-point $T_{\mathrm{b}}$ or an increase in the 
variability of $T_{\mathrm{b}}$ in a direction that increases the benefitto-cost ratio (Angilletta et al. 2010).

Compared to the number of studies on rest-phase heterothermy, thermoregulation in small, free-ranging endotherms under warm conditions has received comparatively little attention (Fick et al. 2009). An improved understanding of how environmental factors affect the costs of thermoregulation and, more importantly, the abilities of organisms to respond to different climatic conditions, is essential in the face of growing concerns about the vulnerability of endotherms to climate change (Welbergen et al. 2008, Fuller et al. 2010, McKechnie and Wolf 2010, Boyles et al. 2011a, Glanville et al. 2012). One of the main predictions of bioclimatic envelope models is that populations near the climatic extremes of species' distributions, where thermoregulatory costs are presumably high, are performing suboptimally and are at greater risk of extinction (Thomas et al. 2004). However, if populations are physiologically adapted (genetic variation across generations and/or plastic adjustments) to their respective climates, species may be capable of maintaining high levels of performance throughout their geographic ranges (Chown et al. 2010, Glanville et al. 2012).

Selection pressures on thermoregulatory ability during an animal's rest phase probably favor reduced energy expenditure brought about through facultative reductions in $T_{\mathrm{b}}$ (Pravosudov and Lucas 2000, McKechnie and Lovegrove 2002), but selection pressures acting during the active phase are likely to favor a $T_{\mathrm{b}}$ range appropriate for high-activity performance and endurance over a range of environmental conditions (Heinrich 1977, Angilletta et al. 2010). The regulation of an optimal, active-phase $T_{\mathrm{b}}$ is likely to influence foraging efficiency, reproductive effort, and, ultimately, evolutionary fitness (Heinrich 1977). A $T_{\mathrm{b}}$ too far below the optimal range could result in reduced performance (Angilletta et al. 2003, 2010), whereas a $T_{\mathrm{b}}$ above the optimal range carries with it the risk of lethal hyperthermia, because the range of $T_{\mathrm{b}}$ that an organism can tolerate above normal $T_{\mathrm{b}}$ is generally narrow (Dawson 1954).

Heat dissipation through evaporative cooling can constitute a major cost of thermoregulation during the active phase, especially when the environmental temperature exceeds $T_{\mathrm{b}}$ (or, more specifically, the animal's surface temperature), and because evaporative water loss (EWL) increases rapidly with increasing air temperature $\left(T_{\text {air }}\right)$ (Wolf 2000). Many endotherms are thought to reduce this cost by storing heat (facultative hyperthermia) during periods of heat stress, thereby reducing the need for evaporative cooling at high $T_{\text {air }}$ (mammals, reviewed by Mitchell et al. [2002], Cain et al. [2006]; birds, reviewed by Tieleman and Williams [1999]).

Deserts provide ideal environments for examining relationships between thermoregulation and environmental factors (Wolf 2000). The large fluctuations in $T_{\text {air }}$ that occur daily can result in endotherms experiencing $T_{\text {air }}$ both above and below their TNZs in the space of a few hours. Desert birds are exposed to these $T_{\text {air }}$ fluctuations to a greater degree than taxa such as reptiles and small mammals because few diurnal avian species make use of thermally buffered microsites below ground (Bartholomew and Cade 1963, Williams et al. 1999, Wolf 2000). Limited food resources often force desert birds to forage during hot weather (Tieleman and Williams 2002), posing the potential risk of water and energy expenditure rates exceeding intake rates (du Plessis et al. 2012). Moreover, the scarcity of surface water means that balancing water losses associated with high rates of thermoregulatory EWL may become costly during periods of very hot weather.

Birds inhabiting desert environments are thought to benefit greatly from facultative hyperthermia, which contributes to water savings during heat stress (Tieleman and Williams 1999). However, facultative hyperthermia as a physiological adaptation does not appear to be restricted to desert birds. There is no evidence that desert species elevate their $T_{\mathrm{b}}$ more or regulate a higher set-point $T_{\mathrm{b}}$ than non-desert species (Tieleman and Williams 1999). It is noteworthy, however, that all of the data used to test this hypothesis were obtained from birds under laboratory conditions. Under natural conditions, $T_{\mathrm{b}}$ regulation can be strongly affected by variation in resources (energy and water) and activity patterns. For instance, as heat load increases, hydration state should play an important role in the regulation of $T_{\mathrm{b}}$ (Angilletta et al. 2010; see also Maloney and Dawson 1998). Because birds living in hot deserts are more likely to experience water stress than those in cooler, more mesic environments, one might predict that they would maintain a higher $T_{\mathrm{b}}$ (either through facultative hyperthermia or a higher set-point $T_{\mathrm{b}}$ ) to dissipate heat via non-evaporative pathways.

We hypothesized that both active- and rest-phase thermoregulatory patterns are tightly linked to environmental conditions in hot, arid habitats, and investigated the influence of $T_{\text {air }}$ on thermoregulation in an Afrotropical, arid-zone passerine bird during summer at two sites in arid habitats: a desert site with high $T_{\text {air }}$ maxima and low rainfall, and a semi-desert site with cooler and wetter conditions. We tested the predictions that (1) birds would store heat on hot days and that $T_{\mathrm{b}}$ should be positively correlated to $T_{\text {air }}$ by both day and night; (2) reliance on hyperthermia during warm weather should be greater in the population at the desert site, and/or this population should express a higher set-point $T_{\mathrm{b}}$; and (3) the population at the desert site should thermoregulate less precisely during the rest phase than birds from the semi-desert site.

\section{Methods And Materials}

We investigated the effect of $T_{\text {air }}$ on $T_{\mathrm{b}}$ and behavior of an arid-zone endotherm, the White-browed SparrowWeaver Plocepasser mahali (family Ploceidae; order 
Passeriformes; Appendix A: Fig. A1), at two sites, 100 km apart, in the southern Kalahari Desert of South Africa, over two consecutive summer seasons. During the first summer, we collected data from birds at a semi-desert site, Tswalu Kalahari Reserve (TKR, 1100 m above sea level, $27^{\circ} 19^{\prime} \mathrm{S}, 22^{\circ} 25^{\prime} \mathrm{E}$ ), over two periods: 1 December 2010 to 28 December 2010 (period 1) and 14 January to 12 February 2011 (period 2). During the following summer, we obtained additional data from a more arid site, Wildsgenot Game Ranch (WGR, $890 \mathrm{~m}$ a.s.1., $\left.27^{\circ} 04^{\prime} \mathrm{S}, 21^{\circ} 23^{\prime} \mathrm{E}\right), \sim 100 \mathrm{~km}$ due west of TKR, from 21 November to 18 December 2011 (period 3). We subsequently refer to TKR as the semi-desert site and WGR as the desert site (Appendix A: Fig. A2). The desert site is part of the most extreme climatic region occupied by our study species across its southern African range.

During the study, weather data were obtained at both sites using a portable weather station (Vantage Pro2, Davis Instruments, Hayward, California, USA), set $2 \mathrm{~m}$ above ground in the approximate center of each study site. This weather station has an aspirator fan to ensure air movement over the temperature and humidity sensors. We checked the factory calibration of the weather station against a mercury thermometer for $T_{\text {air }}$ and against a regularly calibrated $\mathrm{CO}_{2} / \mathrm{H}_{2} \mathrm{O}$ gas analyzer (LI-840A, LI-COR, Lincoln, Nebraska, USA) for humidity. The weather during period 3 at the desert site was similar to period 1 (the dry season at the semi-desert site), whereas period 2 experienced wet, humid conditions and a less extreme range in temperature (Appendix A: Table A1).

We trapped birds at night (21:00-23:00 hours) in their roost nests using a hand net. At the semi-desert site, we caught 12 individuals on 28 November 2010 (dry season), and 12 individuals on 12 January 2011 (wet season). We caught 13 individuals at the desert site on 20 November 2011. All of the birds were banded with a single aluminum ring and up to three color rings for subsequent identification in the field.

\section{Measurement of body temperature}

On the day of capture, the birds were transported to a veterinary clinic where a registered veterinarian implanted temperature-sensitive data-loggers intra-peritoneally (iButtons, Model DS1922L; Maxim Semiconductors, Dallas, Texas, USA). The iButtons were modified following Lovegrove (2009), by removing the steel casing to reduce their mass to $<1.5 \mathrm{~g}$. However, whereas Lovegrove (2009) soldered the battery onto the circuit board to secure the connection, we found that this method increased the chances of draining the battery, and we therefore glued the battery to the circuit board using an adhesive (Pratley Ezeebond, Krugersdorp, South Africa). We calibrated the iButtons against a mercury thermometer (accurate to $0.1^{\circ} \mathrm{C}$ ) at temperatures between $35^{\circ}$ and $45^{\circ} \mathrm{C}$ at $2.5^{\circ} \mathrm{C}$ intervals. We programmed the iButtons to record data every $10 \mathrm{~min}\left(0.0625^{\circ} \mathrm{C}\right.$ resolution), and coated them in biologically inert surgical wax before implantation. The mean body mass of birds was $42.9 \mathrm{~g}$ (range 35.8-51.0 g) and therefore the implanted iButtons (1.76-2.05 g) weighed $<5.5 \%$ of body mass in all individuals; we ensured that the lightest iButtons were implanted in the smallest individuals. The birds were fully anesthetized during surgery, initially using 4\% isoflorane (supplied through a facial mask), subsequently maintained at $2 \%$ isoflorane. We kept the birds in captivity in a cage $(1 \times 1 \times 1 \mathrm{~m})$ constructed of shade cloth for a maximum of $24 \mathrm{~h}$, providing mealworm larvae and water ad libitum to allow them to recover from surgery before releasing them at the site of capture. We attempted to recapture the birds one month after surgery, either by hand from their roosts, or during the day using mist nets (Ecotone, Gdynia, Poland) and transported all recaptured individuals to the veterinary clinic, where the iButtons where surgically removed following the same procedure as previously described. Finally, all individuals were released at the site of capture. We recovered $T_{\mathrm{b}}$ data from four and five birds during the dry and wet season at the semi-desert site, and seven birds from the dry season at the desert site.

\section{Behavioral observations}

We monitored individuals implanted with dataloggers between 12:00 and 18:00 hours (i.e., the warmest time of day) to link behavioral patterns to $T_{\mathrm{b}}$ measurements. A single focal observation per day, lasting 10-30 min, was made on a randomly chosen implanted bird. During each focal period we noted behavior at 1-min intervals, and recorded activity state (mobile vs. stationary), general activity (foraging, resting or scanning, preening, calling, nest maintenance, or provisioning chicks). Foraging behavior included running on the ground with intermittent stops to inspect grass tufts, bushes, or plant litter for insects or seeds; pecking at insects; and digging in the ground or plant litter for food. Resting or scanning behavior included perching on the ground, vegetation, or an elevated post; individuals often scanned their surroundings (probably vigilance behavior), preened, or communicated vocally with group members at this time. We also recorded microsite use by recording (1) whether the bird was on the ground or arboreal; (2) if it was associated with vegetation, and (3) the bird's exposure to direct sun (sun/shade/dappled sunlight). Finally, we recorded whether the bird engaged in heat dissipation behavior during any of the previously mentioned activities, i.e., panting (defined as gaping when breathing) and/or wingspreading (defined as lifting the shoulder away from body to facilitate air flow over the underwing). We conducted a total of 10,88 , and 11 focal observations during the first, second, and third data collection periods, respectively.

\section{Data and statistical analyses}

All statistical analyses were done using R ( R Development Core Team 2011). We followed Boyles et 
al. (2011b) and assumed that modal body temperature ( $T_{\text {mod }}$, defined as the most frequently measured body temperature to the nearest $0.1^{\circ} \mathrm{C}$ ), measured at temperatures when the birds were active but unlikely to be experiencing thermal stress, approximated active-phase optimal, or set-point, $T_{\mathrm{b}}$. We determined $T_{\text {mod }}$ for each bird by pooling all $T_{\mathrm{b}}$ measurements made between 06:00 and 10:00 hours. We used analyses of variance (ANOVA) to compare $T_{\bmod }$ between dry and wet seasons at the semi-desert site and the dry season at the desert site. To investigate deviations in $T_{\mathrm{b}}$ from $T_{\bmod }$ during the warmest part of the day (12:00-18:00 hours), we calculated mean $T_{\mathrm{b}}-T_{\text {mod }}$ and maximum $T_{\mathrm{b}}-T_{\bmod }$ for each individual over three time intervals: 12:0014:00, 14:00-16:00, and 16:00-18:00 hours (hereafter referred to as early, mid, and late afternoon). For each time interval, we calculated mean $T_{\text {air }}$ (for each interval, maximum $T_{\text {air }}$ was normally within $1^{\circ} \mathrm{C}$ of mean $T_{\text {air }}$ ) and mean water vapor pressure deficit $(D$, in $\mathrm{kPa})$. We calculated $D$ as the difference in vapor pressure between saturated air $\left(e_{\mathrm{s}}\right.$, the vapor pressure of saturated air at $\left.T_{i}\right)$ and the actual vapor pressure $\left(e_{\mathrm{a}}\right.$, measured by the weather station); see Campbell and Norman (1998). We hypothesized that $D$ should strongly influence the ability of the birds to lose heat through evaporation. However, assessing the role of $D$ in the field is potentially problematic because $D$ is highly dependent on $T_{\text {air }}$. If there was sufficient variation in $e_{\mathrm{a}}$ levels between days, collinearity between $D$ and $T_{\text {air }}$ was less severe because there was a greater range of possible $D$ values at any given $T_{\text {air }}$. However, if $e_{\mathrm{a}}$ did not vary sufficiently in the data set, the degree of collinearity between $D$ and $T_{\text {air }}$ was high in statistical analyses, which can result in unstable model estimates and artificially inflated $P$ values (Zuur et al. 2010). For this reason, before including $D$ as a factor in any of our models, we first assessed the degree of collinearity between $T_{\text {air }}$ and $D$ in each data set using a Spearman's rank correlation and variance inflation factors. We excluded $D$ from models when the variance inflation factors exceeded 10 (following Montgomery and Peck 1992). We used generalized mixed-effects models to test if $T_{\mathrm{b}}$ and behavior were related to $T_{\text {air }}$ and $D$ (if applicable). We used the nlme (Pinheiro et al. 2009) and lme4 (Bates et al. 2007) packages in $\mathrm{R}$, to analyze $T_{\mathrm{b}}$ and behavioral data, respectively. For $T_{\mathrm{b}}$ analyses (absolute and $T_{\mathrm{b}}-T_{\bmod }$ mean and maxima), we included the fixed effects of study period, time of day, and gender as categorical factors, and $T_{\text {air }}, D$, and body mass as covariates. The random effects (fitted through model selection) of individual and date were included in a nested design because $T_{\mathrm{b}}$ measurements for individuals were repeated on 18-28 days. We investigated the extent of daily heterothermy (i.e., $T_{\mathrm{b}}$ variation across the circadian cycle) expressed by each individual by calculating a heterothermy index (HI; Boyles et al. 2011b), using 24-h $T_{\mathrm{b}}$ measurements (midnight to midnight). The HI value quantifies deviation of $T_{\mathrm{b}}$ away from modal $T_{\mathrm{b}}$, and provides a quantitative index of heterothermy.

HI was calculated as

$$
\mathrm{HI}=\sqrt{\frac{\sum\left(T_{\bmod }-T_{\mathrm{b}, i}\right)^{2}}{n-1}}
$$

where $T_{\text {mod }}$ is the modal $T_{\mathrm{b}}$ of an individual, $T_{\mathrm{b}, i}$ is the $T_{\mathrm{b}}$ at time $i$, and $n$ is the number of times $T_{\mathrm{b}}$ is sampled (in our case, 144 during a 24-h period). We assessed variation in daily heterothermy as a function of mean daily $T_{\text {air }}$, study period, sex, and body mass, using individual and date as random factors in a nested design.

In analyses of behavioral data, we calculated the proportion of time (determined by frequency) allocated by each individual to major behavioral activities (i.e., foraging and resting or scanning) for each focal period. Using a binomial model, we evaluated how these behavioral patterns varied as a function of mean $T_{\text {air }}$ and time of day as fixed effects, and individual and date as random factors ( $D$ was highly collinear with $T_{\text {air }}$ in this data set and could not be included in the models). Initially, we ran the models using two potential link functions, logit or cloglog; subsequently, we used the function that provided the lowest Akaike Information Criterion score adjusted for small sizes $\left(\mathrm{AIC}_{\mathrm{c}}\right)$ (Burnham and Anderson 2002). When $\Delta \mathrm{AIC}_{\mathrm{c}}$ for the two logit and cloglog models was $<2$, we assumed a logit function.

In all analyses, we initially entered all relevant factors in a model, subsequently removing factors that were not important in a stepwise manner, based on multi-model inference (Burnham and Anderson 2002), using the R package MuMIn (Barton 2010) to select the model that gave the lowest $\mathrm{AIC}_{\mathrm{c}}$ weighted score. We included all relevant interactions a priori and, when an interaction was not important, it was removed in the final model (Engqvist 2005). For post hoc tests of dependent data sets, we used a multiple comparisons of means post hoc test (i.e., Tukey contrasts for mixed-effects models), using multcomp (Hothorn et al. 2008) and mvtnorm (Genz et al. 2011).

We also investigated the effects of behavior on $T_{\mathrm{b}}$. Because $T_{\mathrm{b}}$ was measured every $10 \mathrm{~min}$ (hereafter referred to as the $T_{\mathrm{b}}$ interval), we could evaluate the effect of behaviors between consecutive $T_{\mathrm{b}}$ readings on (1) the magnitude and direction of a change in $T_{\mathrm{b}}$, and on (2) $T_{\mathrm{b}}-T_{\bmod }$ at the end of the interval. We categorized activity levels as zero (completely inactive), low $(0 \%<$ activity levels $\leq 50 \%)$, and high $(50 \%<$ activity levels $\leq 100 \%$ ), and compared mean $T_{\mathrm{b}}$ values as a function of activity levels using generalized mixedeffects models with activity level as a fixed effect and individual and day as random effects.

\section{Results}

\section{Body temperature}

The $T_{\mathrm{b}}$ of White-browed Sparrow-Weavers was bimodally distributed (Fig. 1), reflecting a circadian 

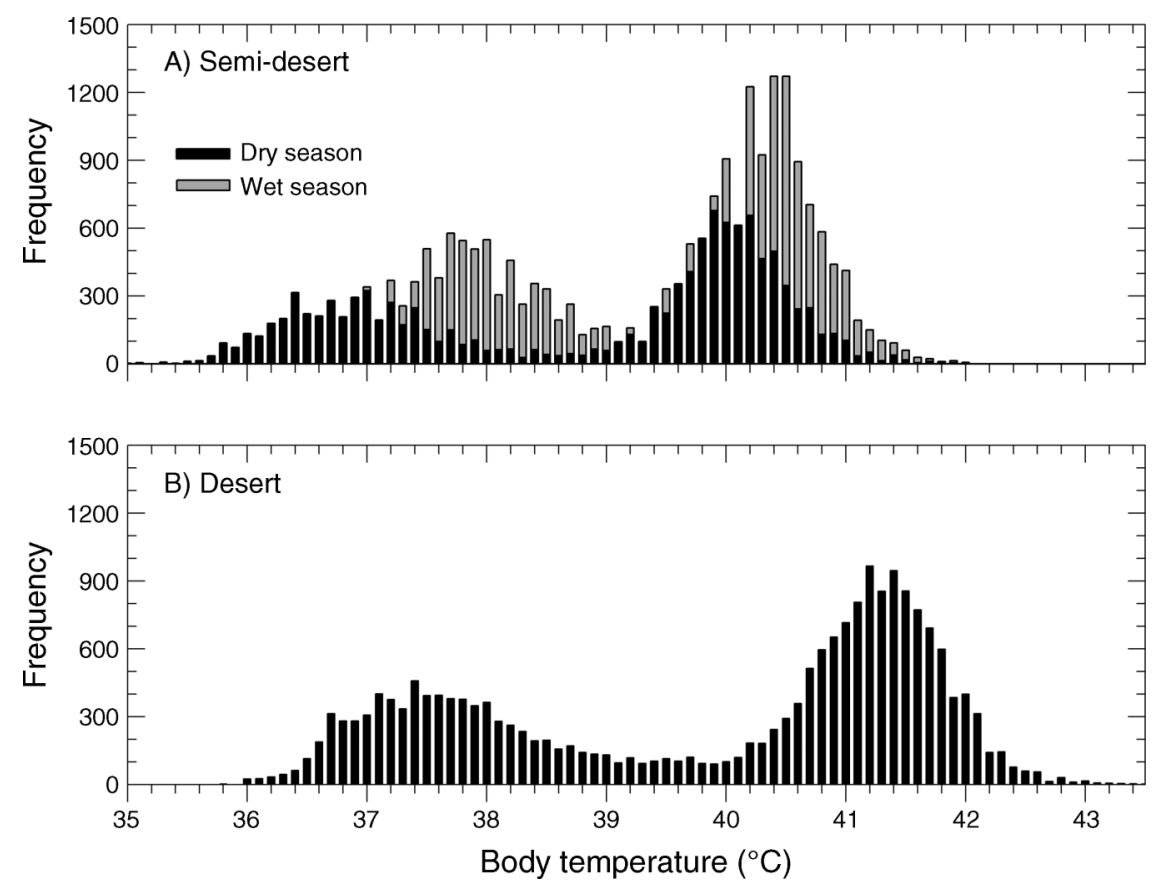

FIG. 1. Distributions of summer body temperatures $\left(T_{\mathrm{b}}\right)$ in White-browed Sparrow-Weavers (Plocepasser mahali) at Tswalu Kalahari Reserve, South Africa (semi-desert) during a dry season (black, $n=4$ birds), and wet season (gray, $n=5$ birds), and at Wildsgenot Game Range (desert; black, $n=7$ birds) during the dry season.

cycle with $T_{\mathrm{b}}$ typically maintained between $40^{\circ}$ and $41^{\circ} \mathrm{C}$ by day and between $35^{\circ}$ and $38^{\circ} \mathrm{C}$ at night (Fig. 2). However, daily fluctuations in $T_{\mathrm{b}}$ were associated with maximum $T_{\text {air }}$ and variation in $D$ (see daily traces in Fig. 2 and Appendix B: Fig. B1). Furthermore, birds at the desert site had a significantly higher $T_{\bmod }\left(41.5^{\circ} \pm 0.2^{\circ} \mathrm{C}\right.$, mean $\pm \mathrm{SD})$ than birds from the semi-desert site $\left(40.1^{\circ}\right.$ $\pm 0.1^{\circ} \mathrm{C}$ and $40.2^{\circ} \pm 0.3^{\circ} \mathrm{C}$, for the dry and wet season, respectively) $\left(F_{2,13}=61.55, P<0.001\right.$; Fig. 1$)$.

Air temperature, $D$, time of day, and study period were important predictors of thermoregulatory patterns (Appendix C: Table C1). Mean and maximum $T_{\mathrm{b}}$, when analyzed as absolute measurements or as deviations from $T_{\text {mod }}$, i.e., $T_{\mathrm{b}}-T_{\text {mod }}$, were linked positively to $T_{\text {air }}$ (for mean $T_{\mathrm{b}}, \chi_{1,819}^{2}=95.13, P<0.001$; for maximum $T_{\mathrm{b}}, \chi_{1,819}^{2}=173.7, P<0.001$ ) and negatively to $D$ (for mean $T_{\mathrm{b}}, \chi_{1,819}^{2}=42.59, P<0.001$; for maximum $T_{\mathrm{b}}$, $\left.\chi_{1,819}^{2}=56.14, P<0.001\right)$, and the interaction between $T_{\text {air }}$ and VPD was significant in all models (for mean $T_{\mathrm{b}}$, $\chi_{1,819}^{2}=33.97, P<0.001$; for maximum $T_{\mathrm{b}}, \chi_{1,819}^{2}=$ $34.51, P<0.001)$. During periods of high $T_{\text {air }}\left(>36^{\circ} \mathrm{C}\right)$, mean $T_{\mathrm{b}}$ was typically above $T_{\bmod }$ (Figs. 2 and 3 ), whereas maximum $T_{\mathrm{b}}$ exceeded $T_{\bmod }$ by up to $2.3^{\circ} \mathrm{C}$. Mean and maximum $T_{\mathrm{b}}$ were generally higher than $T_{\bmod }$ at low $D$; for example, at mild $T_{\text {air }}\left(28-32^{\circ} \mathrm{C}\right)$, mean and maximum $T_{\mathrm{b}}$ were above $T_{\bmod }$ at $D<3 \mathrm{kPa}$ (Fig. 4). There was also a highly significant difference in both mean and maximum $T_{\mathrm{b}}$ as a function of time of day (for mean $T_{\mathrm{b}}, \chi_{2,819}^{2}=598.7, P<0.001$; for maximum $T_{\mathrm{b}}$, $\left.\chi_{2,819}^{2}=254.0, P<0.001\right)$. Mean $T_{\mathrm{b}}$ was significantly higher during mid and late afternoon than during early afternoon (Tukey HSD, $P<0.001$ ), and the interaction between time of day, $T_{\text {air }}$, and $D$ was also significant (for mean $T_{\mathrm{b}}, \chi_{2,819}^{2}=123.1, P<0.001$; for maximum $T_{\mathrm{b}}$, $\left.\chi_{1,819}^{2}=74.09, P<0.001\right)$.

Absolute mean and maximum $T_{\mathrm{b}}$ during the warmest part of the day varied significantly between study periods (for mean $T_{\mathrm{b}}, \chi_{2,13}^{2}=57.08, P<0.001$; for maximum $\left.T_{\mathrm{b}}, \chi_{1,819}^{2}=54.76, P<0.001\right)$, and were significantly higher (Tukey HSD, $P<0.001$ ) at the desert site compared to the semi-desert site (both in the dry and wet seasons; Fig. 3A, C). In contrast, mean and maximum daily $T_{\mathrm{b}}-T_{\bmod }$ were significantly higher (Tukey HSD, $P<0.001$ ) in birds at the semi-desert site than in birds at the desert site (Fig. 3 B, D). In these models, the interaction between study period, $T_{\text {air }}$, and $D$ was significant (for mean $T_{\mathrm{b}}, \chi_{2,819}^{2}=6.537, P=0.038$; for maximum $T_{\mathrm{b}}, \chi_{1,819}^{2}=56.14, P=0.008$ ).

The overall mean daily $\mathrm{HI}$ value for all birds was $2.1^{\circ}$ $\pm 0.5^{\circ} \mathrm{C}$ (mean $\pm \mathrm{SD}$ ) and there was no effect of sex or body mass on HI. However, daily HI was significantly and inversely related to mean daily $T_{\text {air }}\left(\chi_{1,394}^{2}=316.8, P\right.$ $<0.001)$. There was also a significant effect of study period $\left(\chi_{2,13}^{2}=55.53, P<0.001\right.$; Fig. 5), and a significant interaction between mean $T_{\text {air }}$ and study period $\left(\chi_{2,394}^{2}=\right.$ 57.79, $P<0.001)$. The magnitude of heterothermy was greater in the desert birds $\left(\mathrm{HI}=2.4^{\circ} \pm 0.3^{\circ} \mathrm{C}\right)$ than in the semi-desert population in both dry and wet seasons (Tukey HSD, $P<0.05$ and $P<0.001$, respectively). The semi-desert population expressed a greater magnitude of heterothermy during the dry season $(\mathrm{HI}=2.1 \pm$ $\left.0.3^{\circ} \mathrm{C}\right)$ than during the wet season $\left(\mathrm{HI}=1.6 \pm 0.2^{\circ} \mathrm{C}\right.$; 

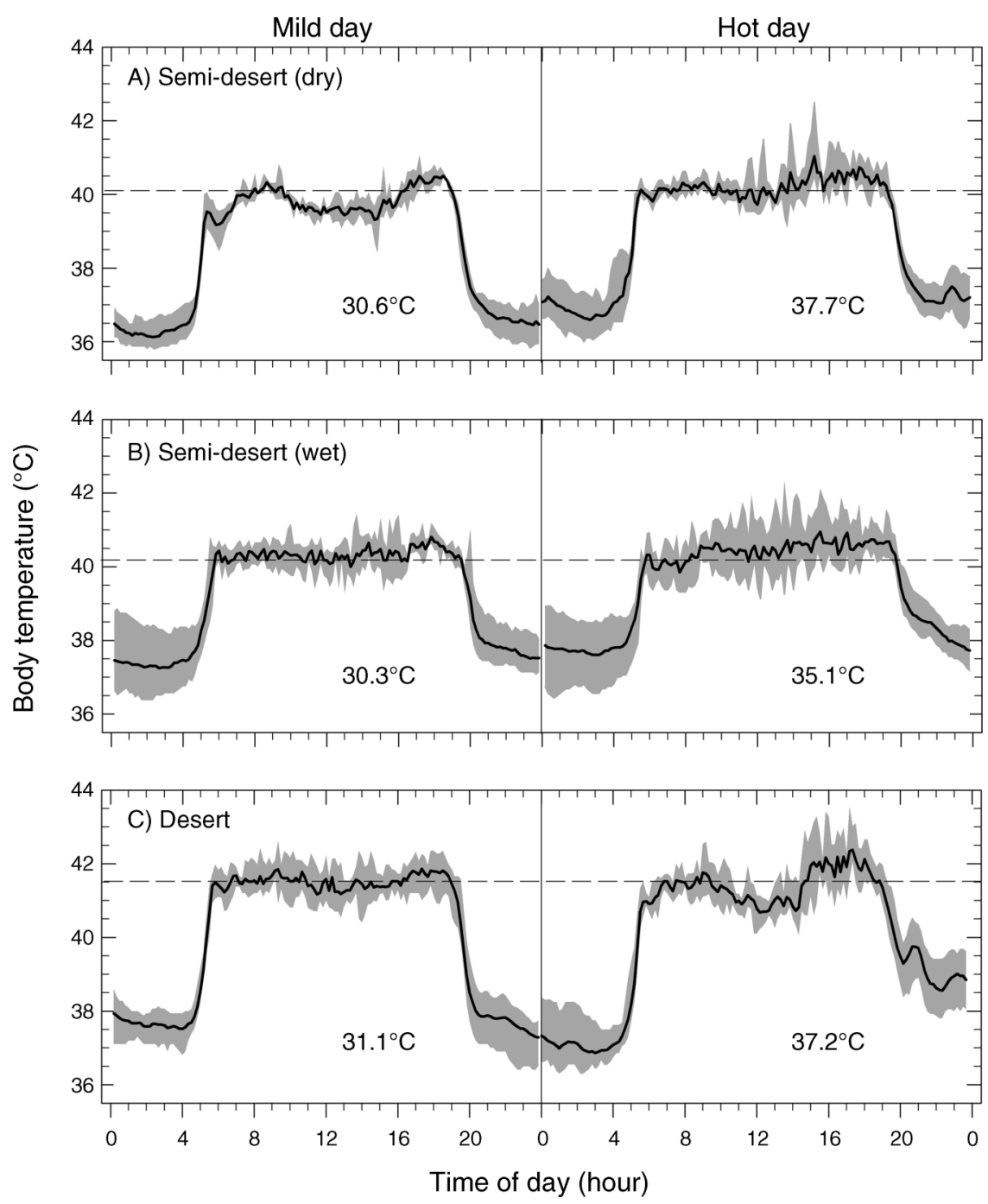

FIG. 2. Traces of summer body temperature in White-browed Sparrow-Weavers on two representative days (mild and hot) at (A) Tswalu Kalahari Reserve (semi-desert) during a dry season $(n=4$ birds, December 2010) and (B) during a wet season $(n=5$ birds) and (C) at Wildsgenot Game Range (desert) during the dry season ( $n=7$ birds). Mean $T_{\mathrm{b}}$ is indicated by the black line, and the range in $T_{\mathrm{b}}$ (minimum and maximum) by the gray area. The maximum $T_{\text {air }}$ values measured on the representative days are displayed inside each panel, and the horizontal dashed line represents the mean modal $T_{\mathrm{b}}$ measured during the respective study period. Time is shown as a $24-\mathrm{h}$ day (0, 00:00 hours; 20, 20:00 hours).

Tukey HSD, $P<0.001)$. Whereas there was no significant difference in the slope of HI as a function of mean $T_{\text {air }}$ between the dry and wet season at the semidesert site $(P=0.832)$, the slope was significantly higher at the desert site $(P<0.001)$.

\section{Behavior}

The number of focal observations during the study was low, especially at the desert site, and therefore study period and $D$ could not be included as predictors. The most important factors used in the final model for the behavioral responses are listed in Appendix C: Table C. The average percentage of time spent active during the warmest time of day (12:00-18:00 hours) was 40\% \pm $20 \%$ (mean $\pm \mathrm{SD}$ ); more than $95 \%$ of all active behavior involved foraging on the ground for insects and seeds. Time spent foraging was negatively related to $T_{\text {air }}\left(\chi_{1,110}^{2}\right.$ $=21.816, P<0.001)$, time of day $\left(\chi_{2,110}^{2}=63.238, P<\right.$ $0.001)$, and the interaction between time of day and $T_{\text {air }}$ $\left(\chi_{2,110}^{2}=14.304, P<0.001\right)$. The birds therefore showed a significant increase in time spent resting as $T_{\text {air }}$ increased $\left(\chi_{1,100}^{2}=9.7527, P<0.01\right)$, again depending on time of day $\left(\chi_{2,110}^{2}=29.582, P<0.001\right)$ and the interaction between time of day and $T_{\text {air }}\left(\chi_{2,110}^{2}=6.1325\right.$, $P<0.05)$. These behaviors were significantly related to $T_{\text {air }}$ during early afternoon only (Appendix B: Fig. B2), when birds foraged less $\left(\chi_{1,33}^{2}=24.406, P<0.001\right)$ and spent more time inactive $\left(\chi_{1,29}^{2}=8.245, P<0.01\right)$ as a function of $T_{\text {air }}$. 

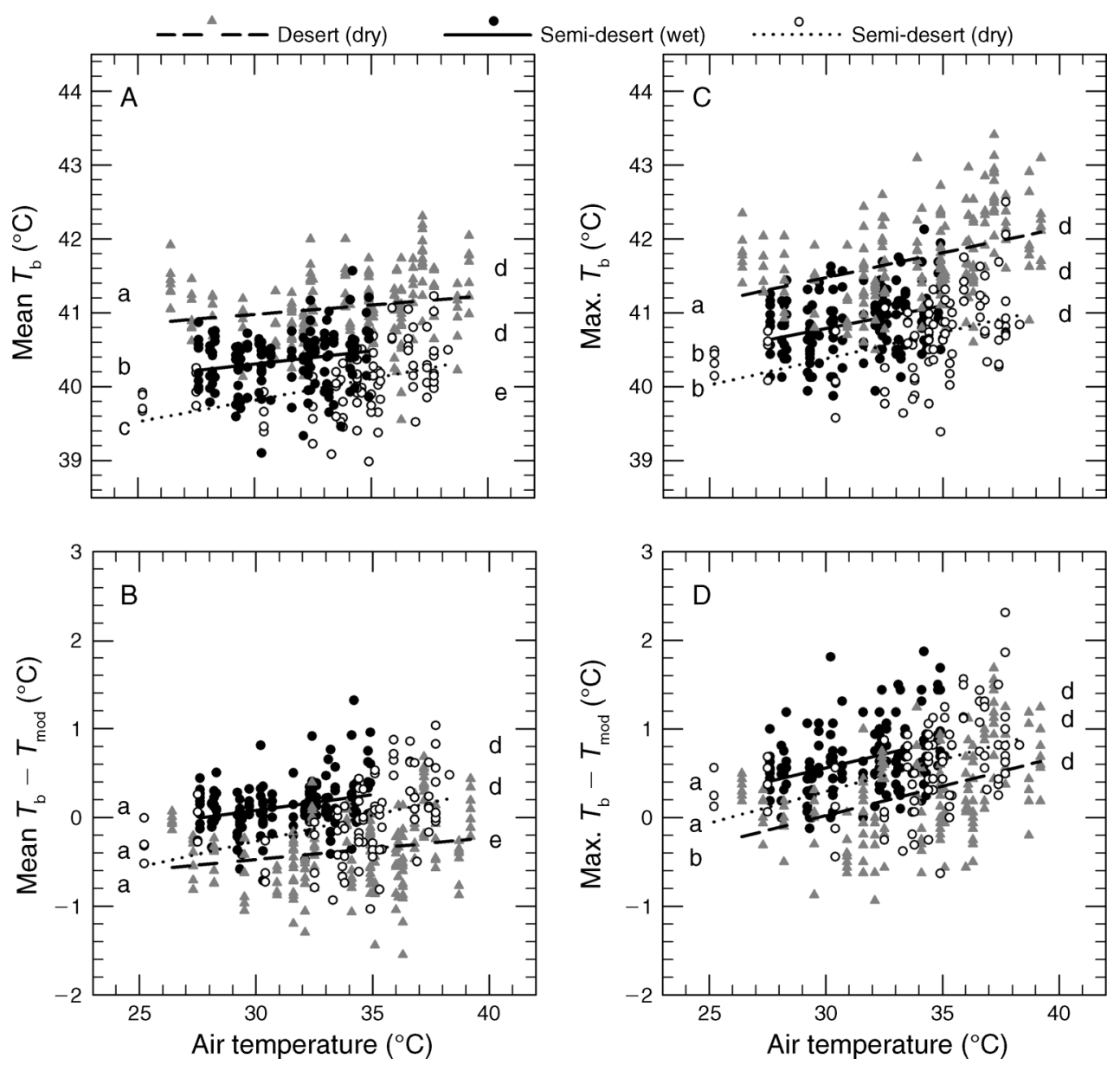

FIG. 3. Body temperature $\left(T_{\mathrm{b}}\right)$ as a function of air temperature $\left(T_{\text {air }}\right)$ in White-browed Sparrow-Weavers measured between 14:00 and 16:00 hours at Tswalu Kalahari Reserve (semi-desert) and Wildsgenot Game Ranch (desert). Body temperatures are displayed as (A) absolute mean $T_{\mathrm{b}}$; (B) mean $T_{\mathrm{b}}$ relative to modal $T_{\mathrm{b}}\left(T_{\mathrm{b}}-T_{\text {mod }}\right)$; (C) absolute maximum $T_{\mathrm{b}}$; and (D) maximum $T_{\mathrm{b}}$ $-T_{\text {mod. }}$ Trendlines indicate a significant relationship $(P<0.05)$, and lowercase letters to the left and right of each trendline indicate significant differences $(P<0.05)$ between intercepts and slopes, respectively, using generalized mixed-effects models.

When birds were foraging at high $T_{\text {air }}$, they reduced the time they spent in full sun $\left(\chi_{1,109}^{2}=26.612, P<\right.$ 0.001 ), depending on time of day and the interaction between time of day and $T_{\text {air }}$. The birds spent significantly less time foraging in the sun at high $T_{\text {air }}$ during early $\left(\chi_{1,29}^{2}=10.982, P<0.001\right)$ and mid afternoon $\left(\chi_{1,47}^{2}=7.179, P<0.01\right)$; microsite use was unrelated to $T_{\text {air }}$ during late afternoon $\left(\chi_{1,33}^{2}=0.018, P=\right.$ 0.894). As a corollary, birds spent significantly more time in shade vs. sun at high $T_{\text {air }}$ during early $\left(\chi_{1,29}^{2}=\right.$ 12.856, $P<0.001)$ and mid afternoon $\left(\chi_{1,47}^{2}=17.545, P\right.$ $<0.001)$, whereas microsite use was highly variable during late afternoon $\left(\chi_{1,33}^{2}=0.684, P=0.408\right)$; see Appendix B: Fig. B2.

Activity level had a significant effect on both change in $T_{\mathrm{b}}$ during a 10 -min interval $\left(\chi_{2,70}^{2}=19.71, P<0.001\right)$ and $T_{\mathrm{b}}$ at the end of the interval $\left(\chi_{2,70}^{2}=8.823, P=\right.$ 0.012 ). When completely inactive, birds reduced $T_{\mathrm{b}}$, on average, by $0.46^{\circ} \mathrm{C}$ (Tukey HSD, $P<0.01$ ), whereas the direction of $T_{\mathrm{b}}$ change was generally positive when birds were active. Similarly, $T_{\mathrm{b}}$ was significantly higher $\left(>0.34^{\circ} \mathrm{C}\right.$, on average; Tukey HSD, $\left.P<0.05\right)$ than $T_{\text {mod }}$ when individuals were active. There was no difference in the direction or magnitude of $T_{\mathrm{b}}$ change between high and low activity levels (Tukey HSD, $P=$ 0.752 and $P=0.100$, respectively).

\section{Heat dissipation}

Panting behavior started when $T_{\text {air }}>28^{\circ} \mathrm{C}$ (Fig. 6A). Time spent panting was positively related to $T_{\text {air }}\left(\chi_{1,110}^{2}\right.$ $=37.33, P<0.001)$, but was also influenced by time of day $\left(\chi_{2,110}^{2}=19.92, P<0.001\right)$ and the interaction between time of day and $T_{\text {air }}\left(\chi_{1,110}^{2}=8.63, P<0.05\right)$. We could not empirically verify the effect of humidity on panting because of a strong correlation between $T_{\text {air }}$ and humidity, although most panting behavior below $35^{\circ} \mathrm{C}$ was associated with low $D$ (Fig. 6A). Panting was significantly related to $T_{\text {air }}$ during all time intervals (Fig. 6A), but showed the strongest relationship to $T_{\text {air }}$ during mid afternoon (14:00-16:00 hours, when daily maxi- 


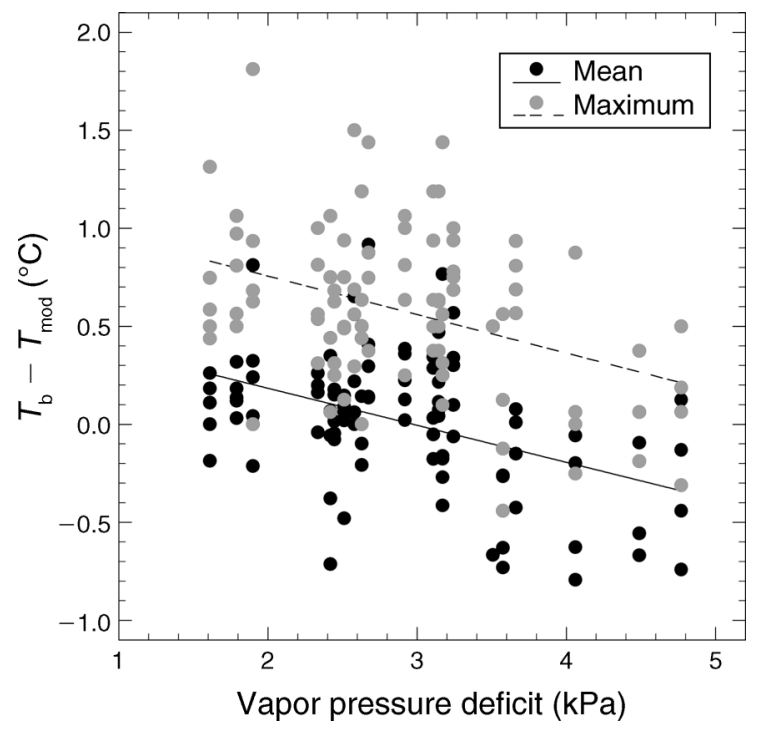

FIG. 4. Mean (black) and maximum (gray) body temperature $\left(T_{\mathrm{b}}\right)$ relative to modal $T_{\mathrm{b}}\left(T_{\mathrm{b}}-T_{\text {mod }}\right)$ in White-browed Sparrow-Weavers at Tswalu Kalahari Reserve (semi-desert dry and wet season data pooled) as a function of vapor pressure deficit $(D)$ measured between 14:00 and 16:00 hours, including only days when maximum $T_{\text {air }}$ was between $28^{\circ}$ and $32^{\circ} \mathrm{C}$. On these days, $T_{\mathrm{b}}$ was not related to $T_{\text {air }}(P=0.185)$, but showed a significant negative relationship with $D(P<0.001)$. In this model, variation in $D$ was most strongly driven by day-to-day variation in dew point temperatures, ranging from $1.4^{\circ}$ to $19.5^{\circ} \mathrm{C}$

mum $T_{\text {air }}$ peaked on most days). In a separate model, we found that panting was not significantly related to activity levels, but the interaction between activity level, time of day, and $T_{\text {air }}$ was significant $\left(\chi_{3,110}^{2}=9.000, P<\right.$ 0.05 ), and the birds panted more when active at high $T_{\text {air }}$.

Wing-spreading behavior was significantly related to $T_{\text {air }}\left(\chi_{1,110}^{2}=56.27, P<0.001\right)$ and time of day $\left(\chi_{2,110}^{2}=\right.$ $7.69, P=0.021)$, although the interaction between time of day and $T_{\text {air }}$ was insignificant in explaining this behavior. Time spent wing-spreading increased at $T_{\text {air }}$ above $30^{\circ} \mathrm{C}$ (Fig. 6B) and was higher during early afternoon (Tukey HSD, $P<0.05$ ), than during mid and late afternoon (Tukey HSD, $P<0.05$ ). In contrast to panting, wingspreading behavior was unrelated to activity levels $\left(\chi_{1,110}^{2}\right.$ $=0.712, P=0.399$ ).

We linked each individual's $T_{\mathrm{b}}$ to its heat dissipation behavior during the first 5 min after $T_{\mathrm{b}}$ was measured. This analysis showed that $T_{\mathrm{b}}$ (relative to $T_{\mathrm{mod}}$ ) was a significant predictor of time spent panting and/or wingspreading, with birds panting and/or wing-spreading more when $T_{\mathrm{b}}>T_{\mathrm{b}}-T_{\bmod }$ (for panting, $\chi_{1,111}^{2}=11.129$, $P<0.001$; for wing-spreading, $\chi_{1,111}^{2}=12.042, P<$ $0.001)$.

\section{DisCUSSION}

Our data provide evidence that $T_{\mathrm{b}}$ patterns in Whitebrowed Sparrow-Weavers are significantly linked to $T_{\text {air }}$ during both active and rest phases. When $T_{\text {air }}$ approached $T_{\mathrm{b}}\left(T_{\mathrm{air}}>37^{\circ} \mathrm{C}\right)$ during the day, $T_{\mathrm{b}}$ was up to $2.3^{\circ} \mathrm{C}$ above $T_{\text {mod }}$, these patterns being further influenced by interactions involving humidity, time of day (probably resulting from daily rhythms in activity and thermoregulation), and activity levels. However, we did not find support for the prediction that desert birds were more likely than semi-desert birds to express hyperthermia, i.e., elevations in $T_{\mathrm{b}}$ relative to their $T_{\text {mod }}$. Overall, however, the desert birds had a higher $T_{\text {mod }}\left(1.3^{\circ}\right.$ and $1.4^{\circ} \mathrm{C}$ for wet and dry seasons, respectively) compared to semi-desert birds, both during cool and warmer periods of the day, supporting the hypothesis that set-point $T_{\mathrm{b}}$ was higher for this population. Although $T_{\mathrm{b}}$ was generally higher in the desert population compared to the semi-desert population during warm periods of the day, $T_{\mathrm{b}}$ levels were more often at or below $T_{\text {mod }}$ in the desert population. If we assume that instances when $T_{\mathrm{b}}$ $>T_{\text {mod }}$ are indicative of hyperthermia, this suggests that desert birds became hyperthermic less frequently than semi-desert birds. The higher set-point $T_{\mathrm{b}}$ probably reduced the occurrence of hyperthermia. Also consistent with our expectations, desert birds had a larger HI and therefore showed greater variation in daily $T_{\mathrm{b}}$ fluctuations as a function of mean daily $T_{\text {air }}$ than did semidesert birds. Thus, within a population, $T_{\mathrm{b}}$ can vary

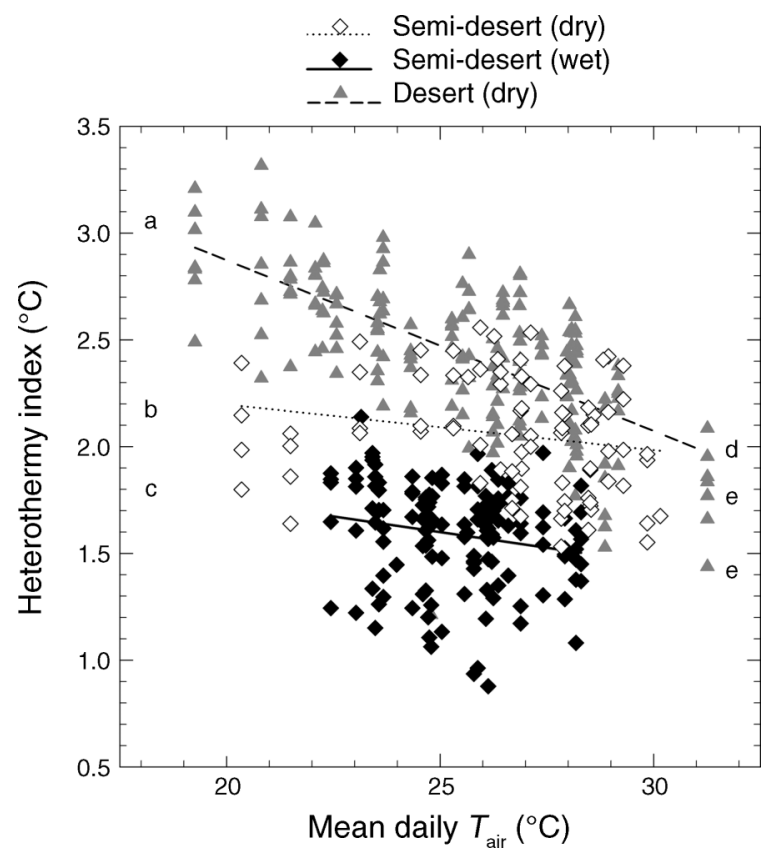

FIG. 5. Daily heterothermy index (HI) during summer as a function of mean daily air temperature $\left(T_{\text {air }}\right)$ in White-browed Sparrow-Weavers at Tswalu Kalahari Reserve (semi-desert), during a dry ( $n=4$ birds) and wet ( $n=5$ birds) season, and at Wildsgenot Game Ranch (desert) during a dry season $(n=7$ birds). Trendlines indicate a significant relationship $(P<0.05)$, and lowercase letters to the left and right of each trendline indicate significant differences $(P<0.05)$ between intercepts and slopes, respectively, using generalized mixed-effects models. 

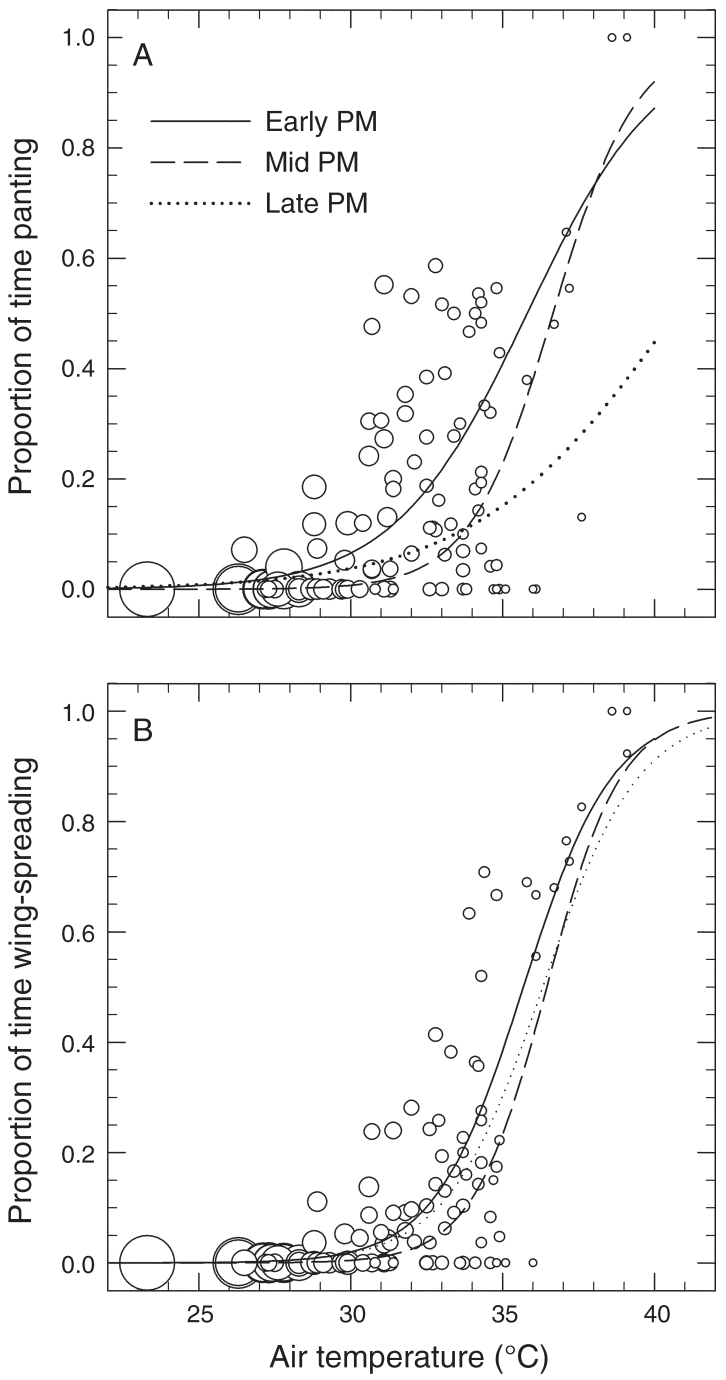

FIG. 6. Proportion of time spent (A) panting and (B) wingspreading by White-browed Sparrow-Weavers as a function of air temperature $\left(T_{\text {air }}\right)$. The logistic curves represent how heat dissipation effects varied between early (12:00-14:00 hours), mid (14:00-16:00 hours), and late (16:00-18:00 hours) afternoon (PM). Sizes of the circles are indicative of levels of humidity (larger circles indicate lower water vapor pressure deficits).

significantly over short time periods as environmental conditions change. These results corroborate other findings that the environment plays an important role in $T_{\mathrm{b}}$ expression at an intraspecific level, both within and between populations (McKechnie et al. 2007, Glanville and Seebacher 2010, Smit et al. 2011, Doucette et al. 2012, Glanville et al. 2012).

These findings challenge the widespread idea that $T_{\mathrm{b}}$ in endotherms is a fixed, species-specific physiological trait (Scholander et al. 1950). For example, Whitebrowed Sparrow-Weavers in this study often showed fluctuations in $T_{\mathrm{b}}$ larger than $3^{\circ} \mathrm{C}$ during their active phase (Fig. 2). The assumption of a constant normo- thermic $T_{\mathrm{b}}$ set-point is often implicit in models linking the energy and water balance of endotherms to environmental and climatic variables (Anderson and Jetz 2005). Moreover, many bioclimatic models predicting climate change impacts rely strongly on this assumption, usually implicitly (Chambers et al. 2005, Kearney and Porter 2009). A variable $T_{\mathrm{b}}$ could greatly reduce thermoregulatory costs in endotherms, and heterothermic responses should be incorporated in energy and water balance models. However, in order to do this, more empirical data on heterothermic responses are needed, not just at species level, but also at the population level if the species' range stretches across different climatic regions. There is thus a greater urgency to understand the ecological or evolutionary factors driving intra- and interspecific variation in endotherm thermoregulatory responses (Angilletta et al. 2010).

It has often been proposed that desert birds should have a higher $T_{\mathrm{b}}$ to facilitate passive heat loss and conserve water (Withers and Williams 1990, Tieleman and Williams 1999, Williams and Tieleman 2005). Tieleman and Williams (1999) tested this hypothesis by compiling data on 28 species and found that $T_{\mathrm{b}}$ did not differ significantly between desert and non-desert birds when $T_{\text {air }}$ was between $25^{\circ}$ and $45^{\circ} \mathrm{C}$. From this observation, based largely on laboratory studies, they concluded that facultative hyperthermia is probably not an adaptation limited to desert birds. Previously, most field $T_{\mathrm{b}}$ data were obtained from freshly killed birds (Wetmore 1921, Brain and Prozesky 1963), and provided no information on relationships with activity and environmental temperature. The present study is the first of which we are aware to investigate daily $T_{\mathrm{b}}$ in more than one population of free-ranging birds under hot environmental conditions. Our findings contrast with those of Tieleman and Williams (1999), revealing that free-ranging birds in a hot, desert site had a higher setpoint $T_{\mathrm{b}}$ than conspecifics in a milder, semi-desert site. Body temperatures measured under laboratory conditions are mostly obtained from captive birds resting in a metabolic chamber under controlled ambient conditions, and arguably would not always be representative of $T_{\mathrm{b}}$ expressed under natural conditions in the same individuals.

The magnitude of the difference (up to $1.4^{\circ} \mathrm{C}$ ) in setpoint diurnal $T_{\mathrm{b}}$ between birds at desert and semi-desert sites was surprising, given that the two populations are only $100 \mathrm{~km}$ apart. White-browed Sparrow-Weavers are highly philopatric and young birds typically delay dispersal for several years. When adult birds do disperse for breeding purposes, they generally relocate to neighboring territories $\sim 200 \mathrm{~m}$ away (Lewis 1982). Variation in thermoregulatory patterns (irrespective of whether the driving force is genetic and/or phenotypic) in response to local climate is therefore more likely in this species than in more mobile or nomadic arid-zone species. Our data do not allow us to partition this 
variation between genetic adaptation and phenotypic plasticity, and common-garden experiments are needed to address this question. However, we note that Ribeiro et al. (2011) recently demonstrated, using genetic markers, that selection for specific physiological traits could occur over small spatial scales (even without any habitat or geographical barriers) across a climatic gradient. Although mean $T_{\text {air }}$ values during the dry season at the desert and semi-desert sites were similar, in the long term the desert site experiences higher $T_{\text {air }}$ extremes (frequently $>40^{\circ} \mathrm{C}$ ) and is much drier during summer. The desert population is therefore more likely to experience higher water demands for evaporative heat loss. By regulating a higher $T_{\bmod }$ during the day, birds at the desert site could maintain a larger $T_{\mathrm{b}}-T_{\text {air }}$ gradient when $T_{\text {air }}<40^{\circ} \mathrm{C}$, reducing the demand for evaporative cooling because they can rely more on non-evaporative pathways to dissipate heat (Calder and King 1974, Tieleman and Williams 1999). Weathers (1981), for instance, estimated that a $2.3^{\circ} \mathrm{C}$ increase in $T_{\mathrm{b}}$ in a $32-\mathrm{g}$ bird (Cardinalis sinuatus) results in $50 \%$ savings in total evaporative water loss when $T_{\text {air }}=38^{\circ} \mathrm{C}$. If a higher $T_{\text {mod }}$ (normothermic $T_{\mathrm{b}}$ ) can contribute to similar water savings in White-browed Sparrow-Weavers, this would be highly adaptive during hot, dry periods in the Kalahari Desert.

Interestingly, the higher $T_{\bmod }$ of birds at the desert site meant that this population experienced less hyperthermia (i.e., increases in $T_{\mathrm{b}}$ above $T_{\mathrm{mod}}$ ). Presumably, having a higher $T_{\bmod }$, resulting in a larger $T_{\mathrm{b}}-T_{\text {air }}$ gradient, meant that increases in $T_{\mathrm{b}}$ above the set-point were less likely at the $T_{\text {air }}$ range recorded in this study. Birds with a higher $T_{\bmod }$ potentially could be active longer at high $T_{\text {air }}$ before $T_{\mathrm{b}}$ exceeds $T_{\text {mod }}$. This in turn would decrease the demand for panting, thereby decreasing costs of evaporative heat loss. At the desert site, panting was only observed at $T_{\text {air }}>37^{\circ} \mathrm{C}$, and these birds were also more active than birds at the semi-desert site at $T_{\text {air }}>35^{\circ} \mathrm{C}$. In a more detailed study on heat dissipation, it was found that under similar weather conditions $\left(T_{\text {air }}=39^{\circ} \mathrm{C}\right)$, White-browed Sparrow-Weavers panted $54 \%$ of the time at the semi-desert site, compared to $15 \%$ at the desert site in the Kalahari Desert (B. Smit, G. Louw, R. O. Martin, S. J. Cunningham, A. E. McKechnie, and P. A. R. Hockey, unpublished data)

Thermogenesis during activity can contribute greatly to a bird's body temperature (Bartholomew and Dawson 1958, Dawson and Hudson 1970, Bartholomew 1972, Heinrich 1977, Wilson and Grémillet 1996). Many birds appear to have a high $T_{\mathrm{b}}\left(\sim 43.9^{\circ} \mathrm{C}\right)$ when sustaining high activity levels (Prinzinger et al. 1991). Behavioral observations of White-browed SparrowWeavers implanted with data-loggers showed that activity levels could contribute to $T_{\mathrm{b}}$ changes, although resolution of our $T_{\mathrm{b}}$ measurements was too low to link the type and intensity of activity or immediate microsite selection directly to changes in $T_{\mathrm{b}}$. During cooler weather, $T_{\mathrm{b}}$ was generally below $T_{\text {mod }}$ in both populations (Fig. 3), and birds could afford large increases in $T_{\mathrm{b}}$ before $T_{\mathrm{b}}$ exceeded $T_{\text {mod }}$. In addition, when resting follows periods of activity, any heat gained during activity will be dissipated readily through passive heat loss at cool $T_{\text {air }}$. During warmer weather, however, $T_{\mathrm{b}}$ was generally close to or higher than $T_{\text {mod }}$, and further elevations in $T_{\mathrm{b}}$ above $T_{\bmod }$ could easily result in unregulated, or pathological hyperthermia as a result of further metabolic heat gain during periods of activity (Heinrich 1977). This interaction between external and internal heat loads increases demand for heat dissipation, and probably results in initiation of panting and/or wing-spreading behaviors at a lower $T_{\text {air }}$ than if the bird were completely inactive. For instance, under lowhumidity conditions in the laboratory, resting Whitebrowed Sparrow-Weavers only start panting when $T_{\text {air }}$ $\approx 40-41^{\circ}$ C; M. C. Whitfield, B. Smit, A. E McKechnie, and B. O. Wolf, unpublished data). The potential increase in heat load during periods of activity at high $T_{\text {air }}$ is likely to influence a bird's behavioral decisions (Tieleman and Williams 2002). Our behavioral data show that both activity patterns and time spent in shade were dependent on $T_{\text {air }}$ and that birds started restricting their foraging behavior to shaded microsites at high temperatures, especially during early afternoon when solar radiation levels are high (Appendix B: Fig. B2). In support of this, heat dissipation behavior increased significantly when $T_{\text {air }}>30^{\circ} \mathrm{C}$ (Fig. 6), suggesting that birds were experiencing increased heat loads. Panting is an indication of demand for evaporative cooling, but the function of wing-spreading is not well studied. Wingspreading could facilitate either cutaneous evaporative cooling or dry heat loss though radiative and convective cooling. Further, the interaction effect of $T_{\text {air }}$ and $D$ suggests that on humid days birds may face a greater risk of uncontrolled hyperthermia at a relatively mild $T_{\text {air }}$ when compared to dry days at equivalent temperatures (Powers 1992, Weathers 1997, Walters et al. 2004), and that at a given $T_{\text {air }}$, total EWL would be higher on humid days because the birds are panting more frequently and more intensely than on drier days (see large circles in Fig. 6).

Many authors consider variation in daily fluctuations in $T_{\mathrm{b}}$ that do not meet certain cutoff limits as typical circadian cycles of homeothermy, thereby overlooking the ecological and evolutionary significance of these fluctuations (Boyles et al. 2011b,c). In a previous study, Ferguson et al. (2002) argued that White-browed Sparrow-Weavers are "typical homeotherms" based on the conclusion that these birds showed no evidence of torpor. However, our results show that variation in daily cycles in $T_{\mathrm{b}}$ is strongly influenced by $T_{\text {air }}$ and further varies within and between populations. The magnitude of daily $\mathrm{HI}$ values in this study was driven by nocturnal reductions in $T_{\mathrm{b}}$, because these values showed the greatest deviation from modal $T_{\mathrm{b}}$. The desert population (experiencing the driest conditions) displayed the great- 
est levels of heterothermy, and birds from the semidesert population displayed greater levels of heterothermy during the dry season than in the wet season (Fig. 5). These results provide support for predictions made by Angilletta et al. (2010) that heterothermy is related to an increased costs-to-benefit ratio of remaining homeothermic, because birds showed greater daily variation in thermoregulation patterns during dry periods when food and water availability were probably lower (Seely and Louw 1980). Daily heterothermy levels in the desert birds were also much more strongly related to daily $T_{\text {air }}$ than were those of the semi-desert birds. Despite summer diurnal temperatures often exceeding $35^{\circ} \mathrm{C}$, nocturnal temperatures are frequently below $10^{\circ} \mathrm{C}$ in the southern Kalahari Desert, especially during dry periods when re-radiation levels are high at night. By allowing $T_{\mathrm{b}}$ to decrease with $T_{\text {air }}$, desert birds would conserve energy on cool nights, which may offset diurnal reductions in foraging performance brought about by low food availability and/or high $T_{\text {air }}$ (du Plessis et al. 2012). Daily heterothermy levels in semi-desert birds, on the other hand, showed a stronger relationship to $T_{\text {air }}$ during the dry season than during the wet season. This suggests flexibility in thermoregulatory responses of the semi-desert population to environmental conditions. We argue that high primary productivity associated with unusually high rainfall at the semi-desert site after 1 January 2011 (244 mm of rain in less than three weeks) resulted in increased food availability, and probably allowed the birds at this site to regulate a more precise $T_{\mathrm{b}}$ (Angilletta et al. 2010).

Over the last 50 years there has been a sharp increase in temperature extremes around the globe (IPCC 2007). During this period, the Kalahari region in southern Africa, in particular around Twee Rivieren, Northern Cape (which is near our desert study site), has experienced some of the fastest rates of increase in maximum temperatures and in the frequency of extreme heat in the southern Africa (Kruger and Sekele 2012). We can therefore expect that birds resident in this area are becoming increasingly exposed to temperatures above normothermic $T_{\mathrm{b}}$. During extreme high-temperature weather anomalies, avoidance of lethal $T_{\mathrm{b}}$ and dehydration become key to short-term survival (McKechnie and Wolf 2010, Boyles et al. 2011a, McKechnie et al. 2012). Because the majority of birds resident in this area do not appear to rely on drinking free surface water (B. Smit and A. E. McKechnie, unpublished data), at high environmental temperatures we would expect many of these species to make tradeoffs between foraging and the need to maintain adequate hydration levels, risking a lethal $T_{\mathrm{b}}$ as a corollary. Tieleman and Williams (2002) showed that nutritional status could play a very important role in this trade-off, and birds with low nutritional status will risk foraging at higher $T_{\text {air }}$ than well-fed birds. Our field observations are limited to $T_{\text {air }}$ below $40^{\circ} \mathrm{C}$, but show that even when $T_{\text {air }}<T_{\mathrm{b}}, T_{\text {air }}$ had a significant effect on thermoregu- lation, and in a number of cases during warm periods, $T_{\mathrm{b}}$ exceeded $43^{\circ} \mathrm{C}$. We predict that at $T_{\text {air }}$ above normal $T_{\mathrm{b}}$, White-browed Sparrow-Weavers will be able to continue foraging by allowing their $T_{\mathrm{b}}$ to increase up to $45^{\circ} \mathrm{C}$, as has been observed in Hoopoe-Larks (Alaemon alaudipes) in the Arabian Desert (B. I. Tieleman and J. B. Williams, personal communications). However, more detailed field studies on how foraging behavior and thermoregulation interact at very high $T_{\text {air }}$ are needed to better understand and predict the vulnerability of desert birds to extreme heat events.

\section{Conclusion}

A key finding of our study was relatively large variation in $T_{\mathrm{b}}$, both within and between conspecific populations. These data suggest that an arid-zone passerine responds differently to prevailing weather conditions in two locations over its range, and that it also responds to seasonal changes in weather conditions. Taken together with the data of Glanville et al. (2012), this suggests that the thermal physiology of endotherms is far more flexible than previously thought, and could potentially contribute to the adaptation of populations under changing climatic conditions (Boyles et al. 2011a). In the past, predictions of species' vulnerabilities to climate change have relied heavily on the use of bioclimatic envelopes (Pearson and Dawson 2003). These predictions are based entirely on correlations between a species' current distribution and the prevailing climate experienced within its range. They implicitly assume that physiological responses are speciesspecific, thereby limiting a species' current distribution to its physiological tolerances. However, our findings and those of Glanville et al. (2012) suggest that a species' current range may not be an accurate representation of its climatic tolerance. Finally, our data also reiterate that when predicting species' responses to climate change, their sensitivity (sensu Williams et al. 2008) should be resolved at the population, rather than species, level (Glanville et al. 2012).

\section{ACKNOWLEDGMENTS}

We thank E. Oppenheimer and Son, and Gerhard Scholtz for land access, and the staff at Tswalu Kalahari Reserve and Wildsgenot Game Ranch for logistic support during the study. We are grateful to the Tswalu Foundation for sponsoring a field vehicle and accommodation at Tswalu Kalahari Reserve. We are grateful to Rowan Martin for statistical advice and Susan Cunningham, Karen Hope, Robert Sutcliff, David Nkosi, and Laura Barclay for their help in the field. Barry Lovegrove provided technical advice on iButton miniaturization. We also thank Justin Boyles for commenting on earlier versions of this manuscript, and Berry Pinshow and an anonymous reviewer for constructive criticism. This research was supported by the DST/ NRF Centre of Excellence at the Percy FitzPatrick Institute, and a Sigma XI Grant in Aid of Research to B. Smit. All experimental procedures were approved by the University of Pretoria's Animal Use and Care Committee (clearance \#EC055-10).

\section{Literature Cited}

Anderson, K. J., and W. Jetz. 2005. The broad-scale ecology of energy expenditure of endotherms. Ecology Letters 8:310318. 
Angilletta, M. J., B. S. Cooper, M. S. Schuler, and J. G. Boyles. 2010. The evolution of thermal physiology in endotherms. Frontiers in Bioscience E2:861-881.

Angilletta, M. J., R. S. Wilson, C. A. Navas, and R. S. James. 2003. Tradeoffs and the evolution of thermal reaction norms. Trends in Ecology and Evolution 18:234-240.

Bartholomew, G. A. 1972. Body temperature and energy metabolism. Pages 298-368 in M. S. Gordon, editor. Animal physiology: principles and adaptation. Macmillan, New York, New York, USA.

Bartholomew, G. A., and T. J. Cade. 1963. Water economy of land birds. Auk 80:504-539.

Bartholomew, G. A., and W. R. Dawson. 1958. Body temperatures in California and Gambel's Quail. Auk 75: $150-156$.

Barton, K. 2010. MuMIn: Multi-model inference. R package version 0.13.17. http://cran.r-project.org/web/packages/ MuMIn

Bates, D., S. D., M. D. Bates, and L. Matrix. 2007. The lme4 package. R Package Version 2(1). http://cran.r-project.org/ web/packages/lme4

Boyles, J. G., F. Seebacher, B. Smit, and A. E. McKechnie. 2011a. Adaptive thermoregulation in endotherms may alter responses to climate change. Integrative and Comparative Biology 51:676-690.

Boyles, J. G., B. Smit, and A. E. McKechnie. 2011b. A new comparative metric for estimating heterothermy in endotherms. Physiological and Biochemical Zoology 84:115-123.

Boyles, J. G., B. Smit, and A. E. McKechnie. 2011c. Does use of the torpor cut-off method to analyze variation in body temperature cause more problems than it solves? Journal of Thermal Biology 36:373-375.

Brain, C. K., and O. P. M. Prozesky. 1963. On the body temperature of birds collected on the Carp-Transvaal Museum Namib Desert expedition. Scientific Papers of the Namib Desert Research Station 16:1-8.

Burnham, K. P., and D. R. Anderson. 2002. Model selection and multimodel inference: a practical information-theoretic approach. Second edition. Spinger-Verlag, New York, New York, USA.

Cain, J. W., P. R. Krausman, S. S. Rosenstock, and J. C. Turner. 2006. Mechanisms of thermoregulation and water balance in desert ungulates. Wildlife Society Bulletin 34:570581.

Calder, W. A., and J. R. King. 1974. Thermal and caloric relations of birds. Pages 259-413 in D. S. Farner and J. R. King, editors. Avian Biology. Volume 4. Academic Press, New York, New York, USA.

Campbell, G. S., and J. M. Norman. 1998. An introduction to environmental biophysics. Springer-Verlag, New York, New York, USA.

Chambers, L. E., L. Hughes, and M. A. Weston. 2005. Climate change and its impact on Australia's avifauna. Emu 105:120.

Chown, S. L., A. A. Hoffmann, T. N. Kristensen, M. J. Angilletta, N. C. Stenseth, and C. Pertoldi. 2010. Adapting to climate change: a perspective from evolutionary physiology. Climate Research 43:3-15.

Dawson, W. R. 1954. Temperature regulation and water requirements of the brown and Abert towhees, Pipilo fuscus and Pipilo aberti. Pages 81-123 in G. A. Bartholomew, F. Crescitelli, T. H. Bullock, W. H. Furgason, and A. M. Schechtman, editors. University of California Publications in Zoology. University of California Press, Berkeley, California, USA.

Dawson, W. R., and J. W. Hudson. 1970. Birds. Pages 223-310 in G. C. Whittow, editor. Comparative Physiology of Thermoregulation. Volume 1. Academic Press, New York, New York, USA.

Doucette, L. I., R. M. Brigham, C. R. Pavey, and F. Geiser. 2012. Prey availability affects daily torpor by free-ranging
Australian owlet-nightjars (Aegotheles cristatus). Oecologia 169:361-372.

du Plessis, K. L., R. O. Martin, P. A. R. Hockey, S. J. Cunningham, and A. R. Ridley. 2012. The costs of keeping cool in a warming world: implications of high temperatures for foraging, thermoregulation and body condition of an arid-zone bird. Global Change Biology 18:3063-3070.

Engqvist, L. 2005. The mistreatment of covariate interaction terms in linear model analyses of behavioural and evolutionary ecology studies. Animal Behaviour 70:967-971.

Ferguson, J. W. H., M. J. M. Nijland, and N. C. Bennett. 2002. Simple roost nests confer large energetic savings for sparrowweavers. Journal of Comparative Physiology B 172:137-143.

Fick, L. G., T. A. Kucio, A. Fuller, A. Matthee, and D. Mitchell. 2009. The relative roles of the parasol-like tail and burrow shuttling in thermoregulation of free-ranging Cape ground squirrels, Xerus inauris. Comparative Biochemistry and Physiology A 152:334-40.

Fuller, A., T. Dawson, B. Helmuth, R. S. Hetem, D. Mitchell, and S. K. Maloney. 2010. Physiological mechanisms in coping with climate change. Physiological and Biochemical Zoology 83:713-20.

Genz, A., F. Bretz, T. Hothorn, T. Miwa, X. Mi, F. Leish, and F. Scheipl. 2011. mvtnorm: Multivariate Normal and $t$ Distributions. R package version 0.9-9991. http://cran. r-project.org/package=mvtnorm

Glanville, E. J., S. A. Murray, and F. Seebacher. 2012. Thermal adaptation in endotherms: climate and phylogeny interact to determine population-level responses in a wild rat. Functional Ecology 26:390-398.

Glanville, E. J., and F. Seebacher. 2010. Plasticity in body temperature and metabolic capacity sustains winter activity in a small endotherm (Rattus fuscipes). Comparative Biochemistry and Physiology A 155:383-391.

Heinrich, B. 1977. Why have some animals evolved to regulate a high body temperature? American Naturalist 111:623-640.

Hothorn, T., F. Bretz, and P. Westfall. 2008. Simultaneous inference in general parametric models. Biometrical Journal $50: 346-363$.

IPCC. 2007. Climate Change 2007: Fourth Assessment Report of the Intergovernmental Panel on Climate Change. Cambridge University Press, Cambridge, UK.

Kearney, M., and W. Porter. 2009. Mechanistic niche modelling: combining physiological and spatial data to predict species' ranges. Ecology Letters 12:334-350.

Kruger, A., and S. Sekele. 2012. Trends in extreme temperature indices in South Africa: 1962-2009. International Journal of Climatology. http://dx.doi.org/10.1002/joc.3455

Lewis, D. M. 1982. Dispersal in a population of White-browed Sparrow-Weavers. Condor 84:306-312.

Lovegrove, B. G. 2009. Modification and miniaturization of Thermochron iButtons for surgical implantation into small animals. Journal of Comparative Physiology B 179:451-458.

Maloney, S. K., and T. J. Dawson. 1998. Changes in pattern of heat loss at high ambient temperature caused by water deprivation in a large flightless bird, the emu. Physiological Zoology 71:712-719.

McKechnie, A. E., R. A. M. Ashdown, M. B. Christian, and R. M. Brigham. 2007. Torpor in an Afrotropical caprimulgid, the Freckled Nightjar (Caprimulgus tristigma). Journal of Avian Biology 38:261-266.

McKechnie, A. E., P. A. R. Hockey, and B. O. Wolf. 2012. Feeling the heat: Australian landbirds and climate change. Emu 112:i-vii.

McKechnie, A. E., and B. G. Lovegrove. 2002. Avian facultative hypothermic responses: a review. Condor 104: 705-724.

McKechnie, A. E., and B. O. Wolf. 2010. Climate change increases the likelihood of catastrophic avian mortality events during extreme heat waves. Biology Letters 6:253-256. 
Mitchell, D., S. K. Maloney, C. Jessen, H. P. Laburn, P. R. Kamerman, G. Mitchell, and A. Fuller. 2002. Adaptive heterothermy and selective brain cooling in arid-zone mammals. Comparative Biochemistry and Physiology B 131:571-85.

Montgomery, D. C., and E. A. Peck. 1992. Introduction to linear regression analyses. Wiley, New York, New York, USA.

Pearson, R. G., and T. P. Dawson. 2003. Predicting the impacts of climate change on the distribution of species: are bioclimate envelope models useful? Global Ecology and Biogeography 12:361-371.

Pinheiro, J., D. Bates, S. DebRoy, D. Sarkar, and R Development Core Team. 2009. nlme: linear and nonlinear mixed effects models. R package version 3.1-106. http://cran. r-project.org/web/packages/nlme

Powers, D. R. 1992. Effects of temperature and humidity on evaporative water loss in Anna's hummingbird (Calypte anna). Journal of Comparative Physiology B 162:74-84.

Pravosudov, V. V., and J. R. Lucas. 2000. The costs of being cool: a dynamic model of nocturnal hypothermia by small food-caching birds in winter. Journal of Avian Biology 31: 463-472.

Prinzinger, R., A. Preßmar, and E. Schleucher. 1991. Body temperature in birds. Comparative Biochemistry and Physiology 99A:499-506.

R Development Core Team. 2011. R: A language and environment for statistical computing. R Foundation for Statistical Computing, Vienna, Austria.

Ribeiro, M., P. Lloyd, and R. C. K. Bowie. 2011. A tight balance between natural selection and gene flow in a southern African arid-zone endemic bird. Evolution 65:3499-3514.

Scholander, P. F., R. Hock, V. Walters, and L. Irving. 1950. Adaptation to cold in arctic and tropical mammals and birds in relation to body temperature, insulation and basal metabolic rate. Biological Bulletin 99:259-271.

Seely, M. K., and G. N. Louw. 1980. First approximation of the effects of rainfall on the ecology and energetics of a Namib desert dune ecosystem. Journal of Arid Environments 3:25-54.

Smit, B., J. G. Boyles, R. M. Brigham, and A. E. McKechnie. 2011. Torpor in dark times: patterns of heterothermy are associated with the lunar cycle in a nocturnal bird. Journal of Biological Rhythms 26:241-248.

Thomas, C. D., et al. 2004. Extinction risk from climate change. Nature 427:145-148.
Tieleman, B. I., and J. B. Williams. 1999. The role of hyperthermia in the water economy of desert birds. Physiological and Biochemical Zoology 72:87-100.

Tieleman, B. I., and J. B. Williams. 2002. Effects of food supplementation on behavioural decisions of hoopoe-larks in the Arabian Desert: balancing water, energy and thermoregulation. Animal Behaviour 63:519-529.

Walters, T. J., K. L. Ryan, and S. H. Constable. 2004. Thermoregulation by rhesus monkeys at different absolute humidities. Journal of Comparative Physiology B 174:481487.

Weathers, W. 1981. Physiological thermoregulation in heatstressed birds: consequences of body size. Physiological Zoology 54:345-361.

Weathers, W. W. 1997. Energetics and thermoregulation by small passerines of the humid, lowland tropics. Auk 114:341353.

Welbergen, J. A., S. M. Klose, N. Markus, and P. Eby. 2008. Climate change and the effects of temperature extremes on Australian flying-foxes. Proceedings of the Royal Society B 275:419-425.

Wetmore, A. 1921. A study of the body temperature of birds. Smithsonian Miscellaneous Collections 72:1-52.

Williams, J. B., and B. I. Tieleman. 2005. Physiological adaptation in desert birds. BioScience 55:416-425.

Williams, J. B., B. I. Tieleman, and M. Shobrak. 1999. Lizard burrows provide thermal refugia for larks in the Arabian Desert. Condor 101:714-717.

Williams, S. E., L. P. Shoo, J. L. Isaac, A. A. Hoffman, and G. Langham. 2008. Towards an integrated framework for assessing the vulnerability of species to climate change. PLoS Biology 6:2621-2626.

Wilson, R. P., and D. Grémillet. 1996. Body temperatures of free-living African Penguins (Spheniscus demersus) and Bank Cormorants (Phalacrocorax neglectus). Journal of Experimental Biology 199:2215-2223.

Withers, P. C. 1992. Comparative animal physiology. Saunders College Publishing, Fort Worth, Texas, USA.

Withers, P. C., and J. B. Williams. 1990. Metabolic and respiratory physiology of an arid-adapted Australasian bird, the Spinifex Pigeon. Condor 92:961-969.

Wolf, B. O. 2000. Global warming and avian occupancy of hot deserts: a physiological and behavioral perspective. Revista Chilena de Historia Natural 73:395-400.

Zuur, A. F., E. N. Ieno, and C. S. Elphick. 2010. A protocol for data exploration to avoid common statistical problems. Methods in Ecology and Evolution 1:3-14.

\section{Supplemental Material}

\section{Appendix A}

Study species and study site information, including photographs and summary of weather recorded during the study (Ecological Archives E094-102-A1).

\section{Appendix B}

Additional figures on body temperature and behavior patterns of White-browed Sparrow-Weavers (Plocepasser mahali) (Ecological Archives E094-102-A2).

\section{Appendix C}

Final models describing body temperature and behavior in White-browed Sparrow-Weavers (Plocepasser mahali) (Ecological Archives E094-102-A3). 